\title{
Some Aspects of Stress Distribution and Effect of Voids Having Different Gases in MV Power Cables
}

\author{
Avinash S, K. Rajagopala \\ (Department of Electrical \& Electronics, National Institute of Technology Karnataka, Surathkal, India)
}

\begin{abstract}
Partial discharge (PD) may have long time delay from days to years depending on the size and other characteristics of voids under electric stress. Voids may be formed due to expansion and contraction of the cables. Enlargement of voids is due to chemical reaction by discharge byproducts and continuous bombardment of particles ( $\mathrm{N}^{+}$ions). The variation in distribution of stress in the void is influenced by the factors like the size of the void, number of voids along the field distribution, the void orientation, the position of the void and the insulation thickness. The influence of discharge inception voltage on the shape and the location of the void are studied. Field variation inside the cavity, the influence of nearby cavities and the comparison of the various shapes of voids in single and three core cables are studied. The variations in temperature distribution of various gases are studied. Among the various gases, oxygen and nitrogen plays a bigger role during PD activity. Oxygen causes uniform erosion in cavity surface by consuming itself in a closed cavity leaving nitrogen, moisture and other gases to initiate the PD. This will result in faster PD activity than the other gases. These observations are done in COMSOL multiphysics software which uses Finite Element Method (FEM) to solve partial differential equations.
\end{abstract}

Keywords - Partial discharge (PD); Finite element method (FEM); COMSOL multiphysics software; Electric field stress; Voids.

\section{INTRODUCTION}

Partial Discharge plays a significant role in breakdown of the cable insulation. The operational stresses that occur in cable insulation which include thermal, mechanical and electrical effects will vary with time and can cause degradation due to the resulting physical and chemical changes in cable properties. PD's are small electrical discharges produced by local enhancement of the electrical stress. The internal discharge in insulation material and/or at its interface is caused by the strong and inhomogeneous electrical fields that are usually caused by voids [1].With the determination of the magnitude of the electric field and its spatial distribution within the cable, it is possible to set a limit on the voltage rating for a given insulation thickness, or alternatively, for a given voltage rating the optimum insulation thickness to be used in the construction of cables may be determined. The insulation thickness is largely based on industrial experience which is built up on a trial and error basis [2]. It is impossible to produce polymeric insulation without micro-porosity. But even to reduce the size of voids below 50 $\mu \mathrm{m}$ the cost of products will increase during the manufacturing of cables. Under heavy loading conditions, owing to the large difference of thermal expansion coefficients between the polymeric insulation and a conductor, a crescent-shaped air gap will be formed between one side of the conductor and its insulation. Such gap will greatly reduce the partial discharge level of the cable [3].Several types of voids in a power cable are studied. The voids located in butt-gaps with a lens-shape are the most dangerous one in terms of their PD potential [4]. Expressions are derived for determining the PD inception voltage in typical voids in cables. Since the ionization and occurrence of partial discharges within the voids would cause erosion and local deterioration of the insulation, which leads to a complete failure of the cable, hence the importance is given to knowledge of the conductor voltage at which partial discharges takes place inside the void [5].The main degradation products were found to be hydrogen, carbon monoxide, methane and carbon dioxide which are produced in a power cable when exposed to PD activity. Droplets were formed on the surface of XLPE only when an atmosphere containing water and carbon monoxide is present. The droplets were found to be a mixture of simple organic compounds, like formic, acetic and carboxylic acids. If one of the constituents $\mathrm{H}, \mathrm{C}$ or $\mathrm{O}$ is absent no droplets appears [6].

By using FEM, any degree of accuracy is obtained. The finite element method reduces a problem to that of solving a number of simultaneous algebraic equations. The solution of the equations yields the electric field and temperature distribution within the area under consideration [1].COMSOL multiphysics has a multiple tools for all engineering applications, here two modes of applications are used they are namely Electrostatics and Heat transfer modules. In electrostatics module we model the cable for obtaining the electric field, potential distribution and heat transfer module we model the cable for obtaining the temperature distribution and heat transfer through cable. The modeling of cable in electrostatic and thermal model is obtained by using a flow chart and mesh generation using FEM in COMSOL multiphysics software [7]. 


\subsection{Cable model}

\section{ANALYSIS OF ELECTRIC FIELD DISTRIBUTION IN VOIDS}

The simplified cable model is shown in Fig. 1. The present work tries to obtain the electric field and temperature distribution within a XLPE insulated cable containing a void-defect. The finite element model of an XLPE underground cable containing void-defect is developed using the COMSOL multiphysics.

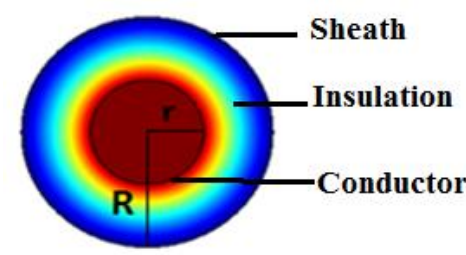

Figure 1: Simplified Cable Model

The parameters of a cable are taken from Cable Corporation of India Ltd (CCI) [7], to study the electrical distribution of single core and three core cable with different arrangement [8].

Table. 1: Parameters of a Cable

\begin{tabular}{|l|c|c|c|}
\hline \multicolumn{1}{|c|}{ Layer } & Diameter $(\mathbf{m m})$ & Material & $\begin{array}{c}\text { Thermal Conductivity } \\
\left(\mathbf{W} / \mathbf{m} . \mathbf{~}_{\mathbf{~ c})}\right.\end{array}$ \\
\hline Conductor & CCI & Copper & 400 \\
\hline Dielectric & CCI & Polyethylene & 0.2 \\
\hline Metallic sheath & CCI & Lead & 35 \\
\hline
\end{tabular}

\subsection{Analysis to demonstrate influence of cylindrical and spherical cavity[4]}

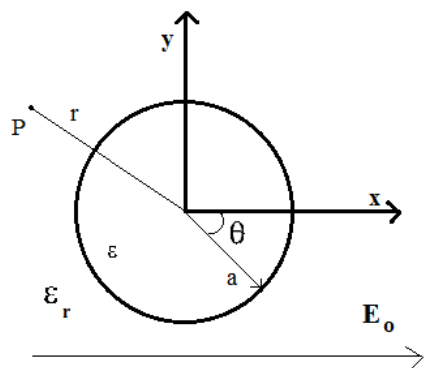

Figure 2: Void Located in the Uniform Field of the Cable [4].

Model of a spherical void within the insulation is shown in Fig. 2. The void is assumed to be filled with air $\left(\varepsilon_{y}=1\right)$. The analytical formulae used here is by assuming there is no free surface change at the insulation surface and cavity boundary, a cylindrical cavity placed in a uniform dielectric field $\left(E_{0}\right)$, with the cavity axis normal to the direction of $\left(E_{0}\right)$, will have electric stress $(\mathrm{E}(\mathrm{r}))$ outside and inside the cavity determined by (1) and (2),

$$
\begin{array}{ll}
E(r)=E_{0}\left(i_{r}\left[1+\left(\varepsilon_{r}-\varepsilon_{0} / \varepsilon_{\mathrm{r}}+\varepsilon_{0}\right) a^{2} / r^{2}\right] \cos \theta-i_{\theta}\left[1-\left(\varepsilon_{\mathrm{r}}-\varepsilon_{0} / \varepsilon_{\mathrm{r}}+\varepsilon_{0}\right) \mathrm{a}^{2} / \mathrm{r}^{2}\right] \sin \theta\right) & \text { for } \mathrm{r}>\mathrm{a} \\
\mathrm{E}(\mathrm{r})=\mathrm{E}_{0}\left(2 \varepsilon_{0} / \varepsilon_{\mathrm{r}}+\varepsilon_{0}\right)\left(\mathrm{i}_{\mathrm{r}} \cos \theta-\mathrm{i}_{\mathrm{\theta}} \sin \theta\right) & \text { for } 0 \leq \mathrm{r}<\mathrm{a}
\end{array}
$$

For a spherical cavity the stress outside and inside the cavity can be calculated by (3) and (4),

$\mathrm{E}(\mathrm{r})=\mathrm{E}_{0}\left(\mathrm{i}_{\mathrm{r}}\left[-1-\left(\varepsilon_{\mathrm{r}}-\varepsilon_{0} / \varepsilon_{\mathrm{r}}+2 \varepsilon_{0}\right) 2 \mathrm{a}^{\mathrm{a}} / \mathrm{r}^{\mathrm{a}}\right] \cos \theta+\mathrm{i}_{\mathrm{\theta}}\left[1-\left(\varepsilon_{\mathrm{r}}-\varepsilon_{0} / \varepsilon_{\mathrm{r}}+2 \varepsilon_{0}\right) 2 \mathrm{a}^{\mathrm{a}} / \mathrm{r}^{\mathrm{a}}\right] \sin \theta\right) \quad$ for $\mathrm{r}>\mathrm{a}$

$\mathrm{E}(\mathrm{r})=\mathrm{E}_{0}\left(-\left(i_{\mathrm{r}} \cos \theta-\mathrm{i}_{\mathrm{Q}} \sin \theta\right)\left(3 \varepsilon_{0} / \varepsilon_{\mathrm{r}}+2 \varepsilon_{0}\right)\right)$

for $0 \leq \mathrm{r}<\mathrm{a}$

Where $\mathrm{a}=$ radius of the cavity.

$\mathrm{r}=$ distance from the cavity center.

In practical, cavities have irregular shapes \& thus analytical solutions for such voids are impossible. Due to singularity point at the corner of a cylindrical cavity, the analytical method is used with simplifying assumption. In such cases, FEM is chosen for computation use. It consists of four main parts: the insulation 
material, the conductor material, the cavity and the cavity surface. The cavity itself is subdivided into small channels which are used for determining the stress distribution inside the cavity.

\subsection{Discharge Inception Voltage[5]}

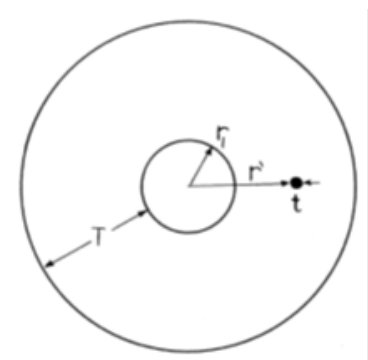

Figure 3: Geometrical Configuration of a Cable

Expressions are derived for the discharge inception voltage $\left(V_{i}\right)$, at which discharge occurs in voids within the insulation of single core cables.

Consider a single-core solid cable of conductor radius $r_{1}$ and insulation thickness T. Let a cavity of thickness ' $t$ ' be within the insulation and at a distance $r$ ' from the conductor center, as shown in Fig. 3. The conductor voltage $\mathrm{V}$ would be given by,

$\mathrm{V}=\int_{\mathrm{r}_{1}}^{r^{v}} \mathrm{E}_{\mathrm{d}} \mathrm{dr}+\int_{\mathrm{r}^{v}}^{\mathrm{r}^{s}+\mathrm{t}} \mathrm{E}_{\mathrm{c}} \mathrm{dr}+\int_{\mathrm{r}^{s}+\mathrm{t}}^{\mathrm{T}_{1}+\mathrm{T}} \mathrm{E}_{\mathrm{d}} \mathrm{dr}$

Where, $\mathrm{E}_{\mathrm{d}}$ and $E_{c}$ are the electric fields in the dielectric \& cavity respectively.

The dielectric field $E_{d}$ at a distance ' $r$ ' from conductor center is given by,

$E_{d}=q / 2 \pi \varepsilon_{0} \varepsilon_{s} r$

Where, $q$ is the charge/unit length of the conductor

$\varepsilon_{g}$ is the relative permittivity of the dielectric

Field inside a small spherical cavity in a dielectric is given by,

$\mathrm{E}_{\mathrm{c}}=\frac{3 \varepsilon_{s}}{1+2 \varepsilon_{s}} \varepsilon_{\mathrm{d}}$

Thus for a spherical cavity (5) becomes,

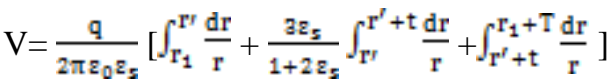

Then,

$\mathrm{V}=\frac{\mathrm{q}}{2 \pi \varepsilon_{0} \varepsilon_{s}}\left[\ln \left(1+\frac{\mathrm{T}}{\mathrm{r}_{1}}\right)+\left(\frac{a \varepsilon_{s}}{1+2 \varepsilon_{s}}-1\right) \ln \left(1+\frac{\mathrm{T}}{\mathrm{r}^{f}}\right)\right]$

The discharge inception voltage $V_{\mathrm{i}}$ is that of the conductor at which the field in the cavity $\mathrm{E}_{\mathrm{c}}$ equals the breakdown strength of the entrained gas $\mathrm{E}_{\mathrm{G}}$ which is given by,

$\mathrm{E}_{\mathrm{G}}=\frac{\pi z_{s}}{1+2 z_{\mathrm{g}}} \frac{\mathrm{q}}{2 \pi z_{0} z_{g^{1}}}$

Hence for the spherical cavity, $V_{i}$ is given by,

$V_{i}=E_{G} r^{\prime}\left\{\frac{1}{a}\left(2+\frac{1}{E_{g}}\right) \ln \left(1+\frac{T}{r_{1}}\right)+\frac{1}{g}\left(1-\frac{1}{E_{z}}\right) \ln \left(\frac{t}{r^{\prime}}\right)\right.$

Where $E_{G}$ depends on the pressure of gas inside the cavity, type of the gas and the thickness of the cavity. 
Similarly $V_{\mathrm{i}}$ for the case of a cylindrical cavity concentric with the conductor is given by,

$V_{i}=E_{G} r^{g}\left\{\frac{1}{g_{s}} \ln \left(1+\frac{T}{r_{1}}\right)+\left(1-\frac{1}{g_{s}}\right) \ln \left(1+\frac{t}{r^{f}}\right)\right\}$

$V_{\mathrm{i}}$ is calculated from (11) and (12) as a function of the cavity thickness ' $\mathrm{t}$ ', for different locations ' $r$ ' of the cavity within the insulation \& for different geometric parameters ' $\mathrm{r}_{1}$ ' \& ' $\mathrm{T}$ ' of the cable.

\section{TEMPERATURE DISTRIBUTION DUE TO OXYGEN AND NITROGEN IN VOIDS}

Partial discharge is due to the high temperature gas production which causes local temperature rise resulting in melting of materials. This finally causes breakdown of cables. Nitrogen (N) PD tends to produce local degradation and it causes micro PD pulses. PD could have very long statistical time lag depending on size and other characteristics of the voids under thermal stress. The number of initial electrons prior to the first discharge in a cavity will depend mainly on its space \& therefore very small for micro voids in the order of micrometers in diameter. After the oxygen is consumed, nitrogen is left facilitates the initiation of micro PD. Oxygen $(\mathrm{O})$ is presumed to be almost all consumed in a closed cavity by PD at its early stage [9].

\subsection{Field Distribution Due To DifFerent ShaPES OF VoIds \\ IV. MODELLING RESULTS}

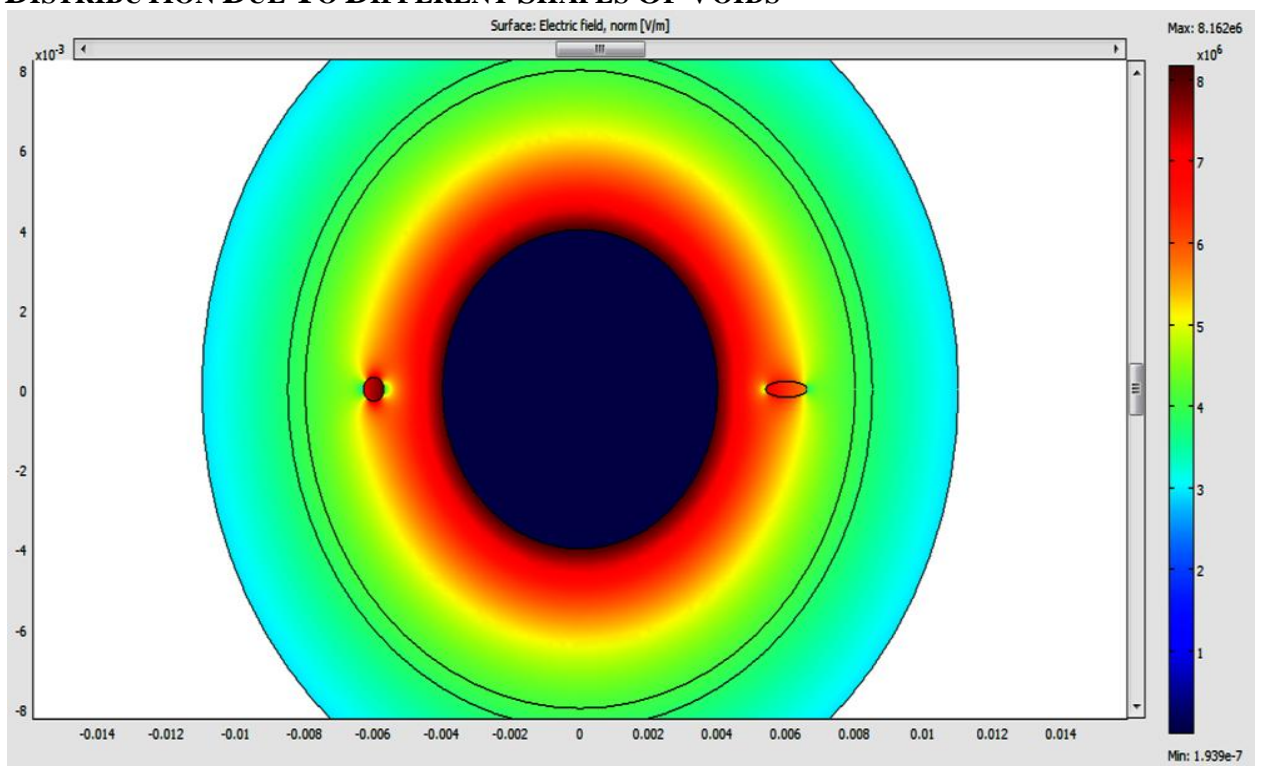

Figure 4: Electrical Field Distribution of SPHerical and Elliptical ShaPES of Voids in a Single Core CABLE

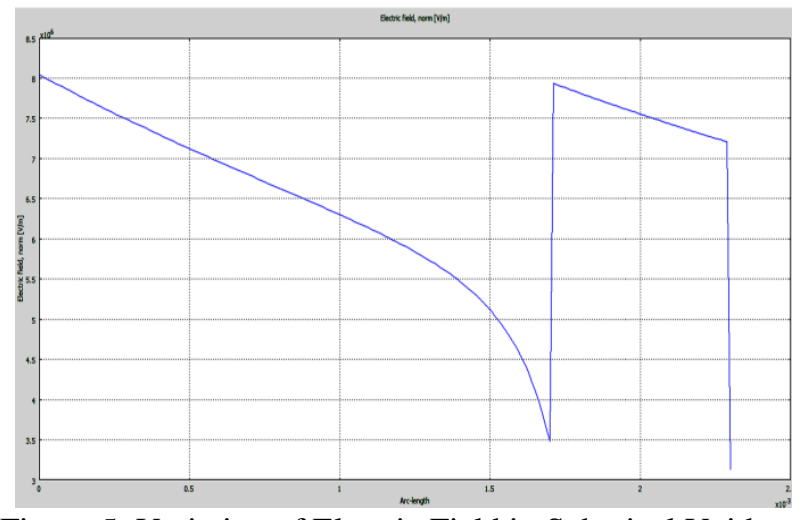

Figure 5: Variation of Electric Field in Spherical Void

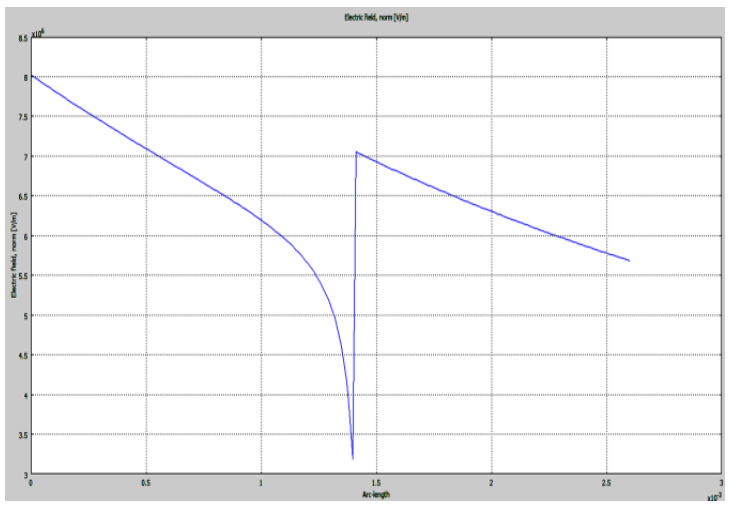

Figure 6: Variation of Electric Field in Elliptical Void 

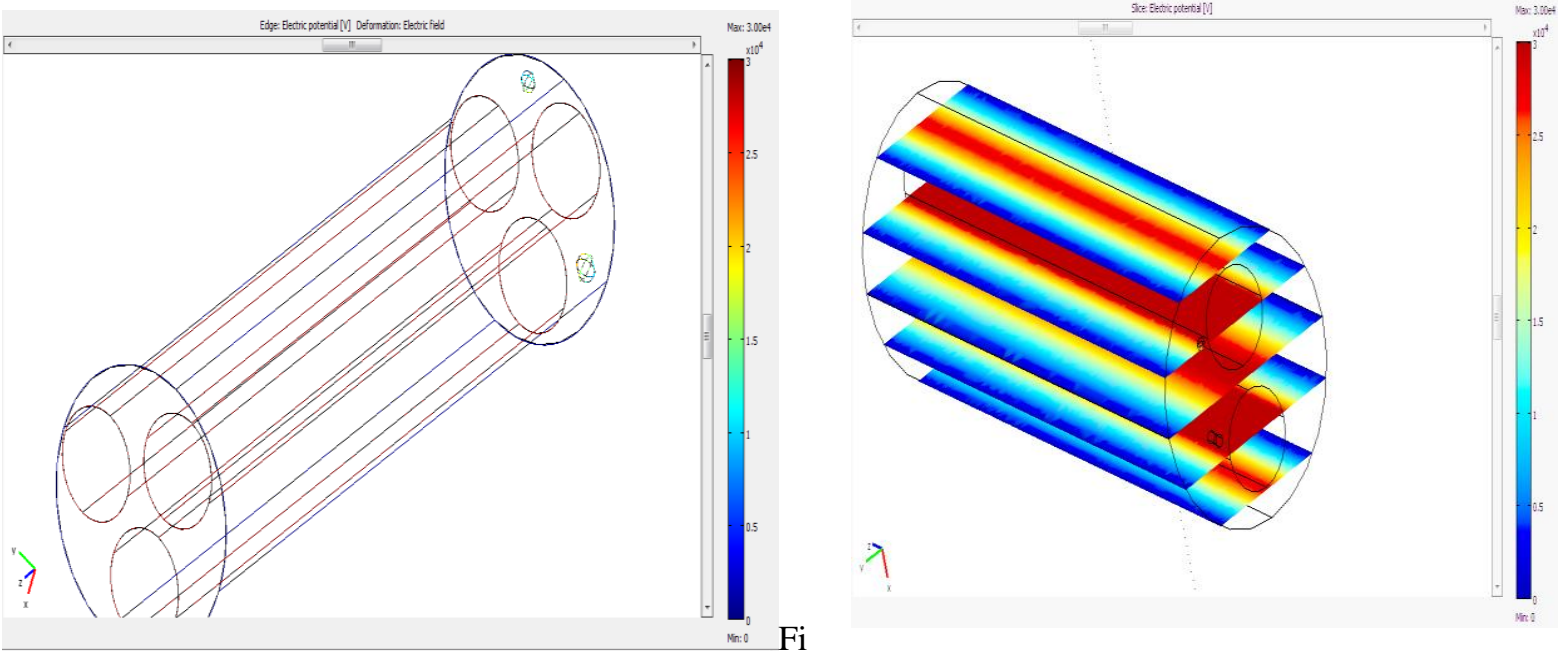

gure 7: 3D plot of Potential Distribution in Two Core Cable with Spherical and Cylindrical Voids

Figure 8: 3D plot of Field Distribution in Three Core Cables with Voids

\subsection{Field Distribution WITH VoIDS IN VARIOUS POSITIONS IN A CABLE}

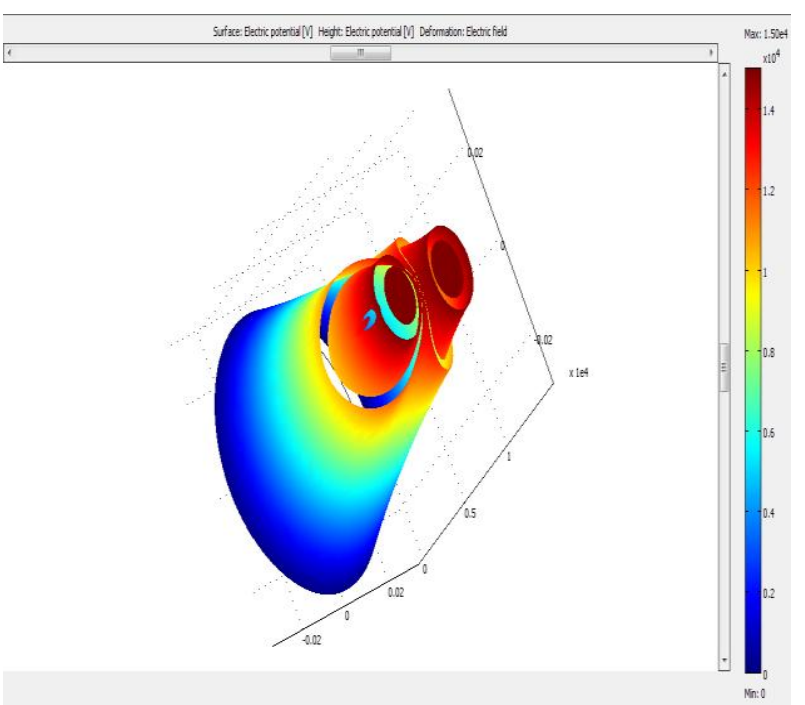

Figure 9: 3D Plot of A Two CoRe CABLE With CABLE VOID AT THE CONDUCTOR

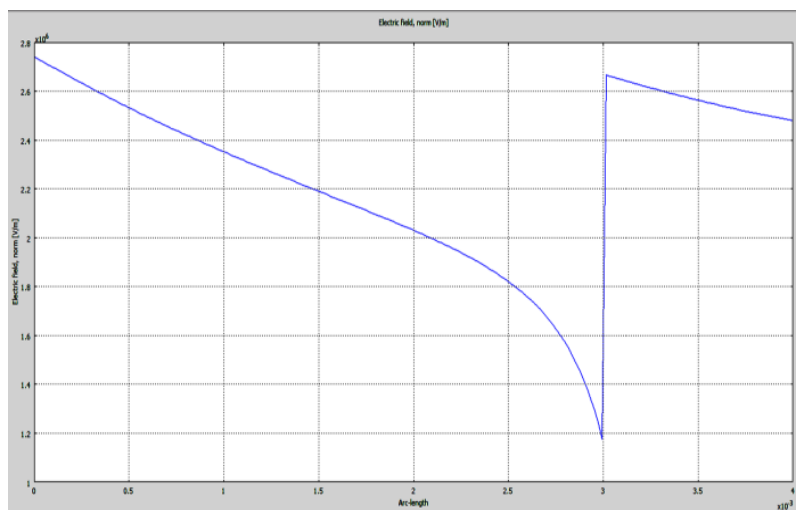

Figure 11: VARIATION OF ElECTRIC FIELD AT VoIDS VOIDS IN THE DIELECTRIC IN TWO CORE CABLE

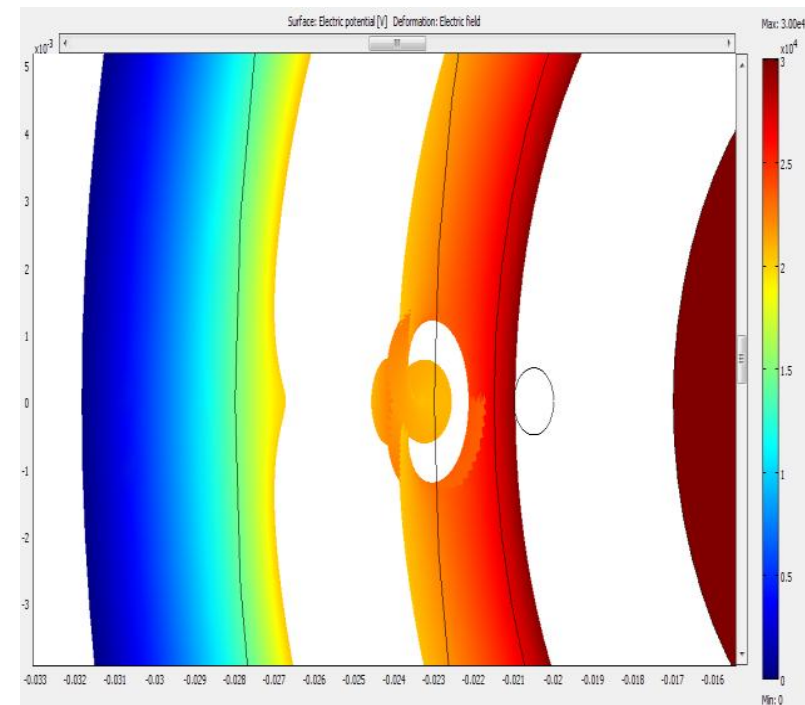

Figure 10: Field DisTRIBUTION IN Two CORE WITH A VOID IN THE DIELECTRIC

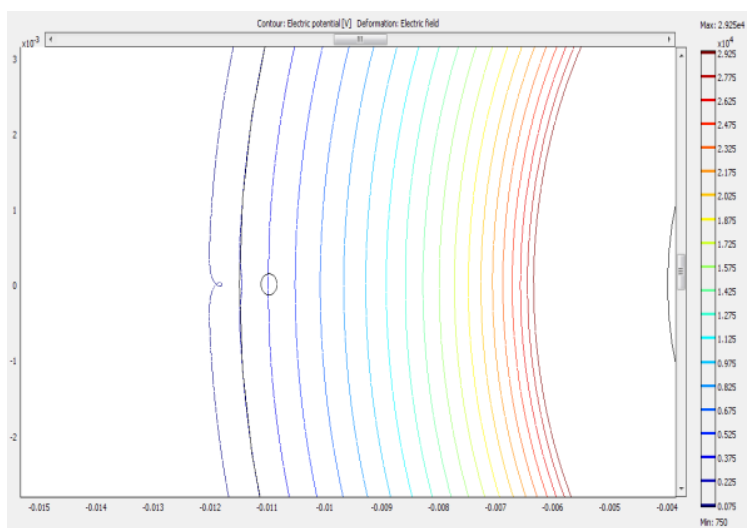

FIgURE 12: VARIATION OF ELECTRIC FIELD AT AT THE SHEATH IN A SINGLE CORE CABLE 


\subsection{FIELD DISTRIBUTION OF VOIDS IN VARIOUS POSITIONS OF A CABLE}

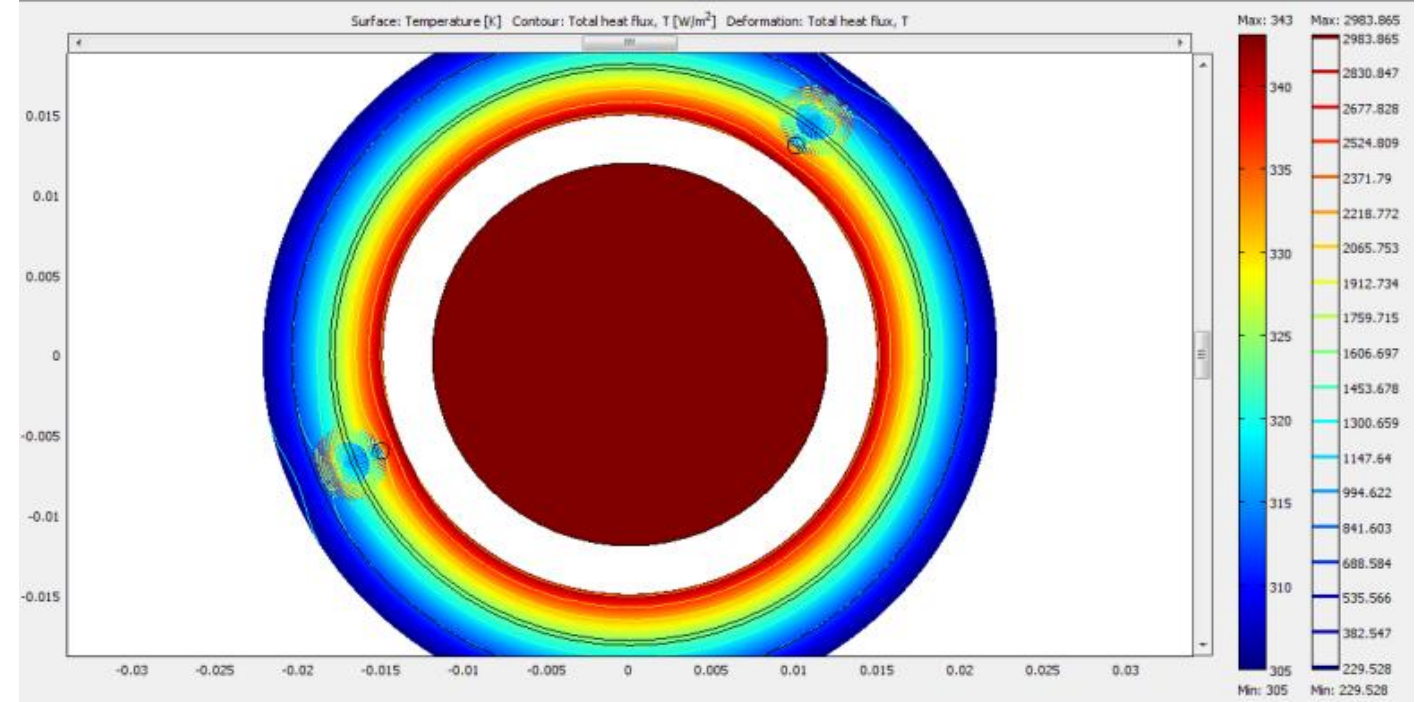

Figure 13: VARIATION OF Total Heat FluX IN A CABLE with VoidS

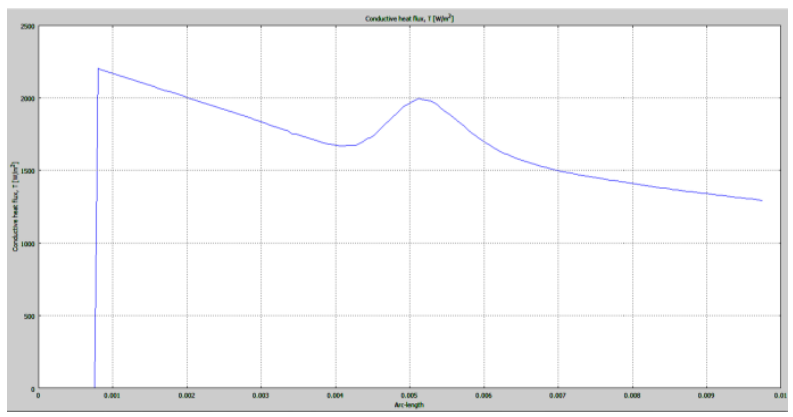

FiguRE 15: VARIATION OF HEAT FLuX ON THE SURFACE OF VOIDS HAVING NiTROGEN

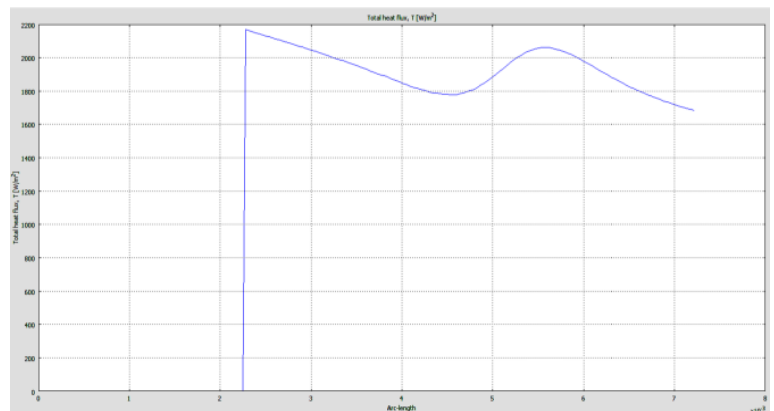

Figure 14: VARIATION OF HEAT FluX ON THE SURFACE OF VOIDS HAVING OXYGEN

\section{DISCUSSIONS}

The electric field distribution in the void is studied by considering different void shapes and positions of the void. The cylindrical voids will have higher stress than spherical and elliptical voids as shown in Fig. 7. The electric stress will be high in spherical void than in the elliptical void as shown in Fig. 4, Fig. 5 and Fig. 6. A 3D plot of field distribution in three core cable with voids is shown in Fig. 8. These observations shows that from different types of voids in power cables, the voids having lens shape will have more electric stress. The larger voids have higher stress. The cavity stress increases as the dielectric permittivity increases. The voids with its axis parallel to the applied field have a higher stress distribution.

$V_{i}$ is calculated using void thickness ' $t$ ' for different positions of the spherical voids. The field distribution of the void near the conductor, at the dielectric and at the sheath is shown in Fig. 9, Fig. 10, Fig. 11 and Fig. 12 respectively. Discharge inception voltage will be smaller when the void is larger and also when the void is nearer to the conductor.

Variation of total heat flux in a cable with voids which is filled with nitrogen and oxygen separately is shown in Fig. 13. Nitrogen is partially consumed by chemical reaction to produce nitrogen compounds in the cavity surface. Partial discharge would takes place with sufficient oxygen. Not only oxygen helps in temperature rise which is shown by comparing Fig. 14 and Fig. 15, but also helps oxidation. Oxygen would be consumed completely during PD in a cable and causes temperature rise which results in thermal breakdown of cables. Therefore oxygen is important than other gases during PD in a cable.

\section{CONCLUSION}

It is observed that cylindrical voids have more electric stress than in spherical and elliptical voids. Among various gases, nitrogen and oxygen plays a significant role during PD. But oxygen consumes completely causing rise in temperature than the nitrogen in the void leading to thermal breakdown of the cable. 


\section{REFERENCES}

[1] M Alsharif, P A Wallace, D M Hepburn and C Zhou, "FEM Modelling of Electric Field and Potential Distributions of MV XLPE Cables Containing Void Defect" Excerpt from the Proceedings of the 2012 COMSOL Conference in Milan.

[2] M. Abdel-Salam and A. Al-Shehri, "Calculation Of Electric Stresses In Three-Core Belted Cables", Conference Record of the 1992 IEEE International Symposium on Electrical Insulation, Baltimore, MD USA, June 7-10, 1992

[3] F.C. Cheng, "Electric Field Distribution Distorted By Voids Inside Power Cables", Proceedings of the 5th Intedonal Conference on Advances in Power System Control, Operation and Management, AF'SCOM 2000, Hong Kong, October $200 O$.

[4] H. N. O, T. R. Blackburn, B. T. Phung, H. Zhang and R. H. Khawaja, "Investigation of Electric Field Distribution in Power Cables with Voids", International Conference on Properties and Applications of Dielectric Materials, Page(s): 637-640, 2006 IEEE.

[5] Abdel-Razak Nosseir, "Calculation of Discharge Inception Voltage Due to the Presence of Voids In Power Cables", IEEE Trans. Electr. Insul, Vol EI-14 No 2, April 1979

[6] Peter H.F. Morshuis, "Degradation of Solid Dielectrics due to Internal Partial Discharge: Some thoughts on progress made and where to go now", IEEE Transactions on Dielectrics and Electrical Insulation Vol. 12, No. 5; October 2005

[7] COMSOL Group Ltd., Stockholm, Sweden: Comsol Multiphysics Software Package Version 3.3a. December 2006.

[8] Power and Control cables "CABLE CORPORATION OF INDIA LTD".

[9] T. Tanaka,"Internal Partial Discharge And Material Degradation" IEEE Transactions on Electrical Insulation Vol. EI-21 No.6, December 1986

[10] Flatabo. N, “ Transient heat conduction problems in power cables solved by the Finite Element Method” Power Apparatus \& System, IEEE TRANSACTION, Page(S):56-63;1973

[11] T.S. Salam, R. Hackam and A.Y. chikhani, "Temperature Distribution of Dielectric Insulation of Distribution Cables", Electric Insulation and Dielectric Phenomena. Conference on Digital Object Identifier : 10.1109/CEIDP.1990.201390, Page(s): 514-519, 1990 IEEE

[12] Harking. E; Kreuger F.H; Morshuis, P.H.F; “Partial Discharges in Three Core Belted Power Cables”, volume: 24; Issue: 4. Page(s): $591-598,1989$ 